\title{
Characterisation of organic colourants in ukiyo-e prints by Fourier transform near infrared fibre optics reflectance spectroscopy
}

\author{
C. Biron, ${ }^{\mathrm{a}, \mathrm{b}^{*}}$ F. Daniel, ${ }^{\mathrm{a}} \mathrm{G}$. Le Bourdon, ${ }^{\mathrm{b}}$ R. Chapoulie ${ }^{\mathrm{a}}$ and L. Servant ${ }^{\mathrm{b}}$ \\ aUniversité Bordeaux Montaigne, IRAMAT-CRP2A - UMR CNRS 5060, Maison de l'Archéologie, Esplanade des Antilles, 33607 Pessac cedex, France. \\ E-mail: carole.biron@u-bordeaux-montaigne.fr \\ bUniversité de Bordeaux, Institut des Sciences Moléculaires - UMR 5255, Bâtiment A12 351 Cours de la Libération, 33405 Talence cedex, France
}

\begin{abstract}
The materials used in Japanese woodblock prints called ukiyo-e, particularly colouring matters, function as indicators on the resources available at a given time and allow us to deepen our knowledge of the cultural purposes and the socio-economic (trading activity, import of new techniques...) impacts of these artworks. The aim of this work is to apply non-invasive near infrared (NIR) spectroscopy which may be helpful for the identification of organic colourings widely employed in ukiyo-e, using fibre optics such as the Fibre Optics Reflectance Spectroscopy (FT-NIR FORS), that has been applied to the cultural heritage field for two decades because of its fast response time in any geometrical configuration. The present work reports results obtained on five organic pigments (indigo, safflower, gamboge, dragon's blood and cochineal), considered as the first step for the building of a database dedicated to specific Japanese colouring matters in order to interpret future hyperspectral data recorded in the Short Wave InfraRed (SWIR) range on a collection of Japanese ukiyo-e prints. The data were obtained with a FT-NIR spectrometer using a probe to collect the specular reflection within the $11,000-4000 \mathrm{~cm}^{-1}$ range, transformed in pseudo-absorbance with $\log (1 / R)$ conversion. Because large bands were observed, originating in overtone and combination modes, a pre-processing smoothing and derivative procedure of the data, together with Principal Component Analysis (PCA) were applied to discriminate the pigments, notably dragon's blood.
\end{abstract}

\section{Introduction}

For several years, the study of paintings enables us to improve our knowledge on the materials (pigments, binders, substrate) and techniques used by the artists in terms of cultural or socioeconomic issues (trade exchanges, importation of new technologies...). However, analyses are often constrained by the fragility of the painted artworks, such as prints, and by curators who forbid any sampling or any move of the artworks out of the museum. Regarding these issues and the various materials used through times, adapted analytical strategies using non-invasive and contactless methods have been developed to investigate painted artworks. ${ }^{1-5}$ Infrared spectroscopy is a selective and sensitive method that is in principle able to evidence most of the materials used in paintings. Since the 2000s, infrared reflectance spectroscopy has been applied to the identification of pigments, dyes and binders using various Fourier Transform Infrared spectroscopy (FTIR) sampling techniques in the mid-infrared range. ${ }^{6-8}$ More recently, near infrared (NIR) reflectance spectroscopy has also been applied thanks to the use of fibre optics (Fibre Optics Reflectance Spectroscopy - FORS) $)^{9-13}$ and allows non-invasive analyses with a fast response time in any geometrical configuration.

The aim of this study is to develop and apply portable NIR spectroscopy for the non-invasive probing of organic colourings employed in the Japanese prints, or ukiyo-e, of the Federico Torralba collection, currently kept in the Museum of Zaragoza, Spain. Japanese ukiyo-e works refer to woodblock prints or paintings produced between the $17^{\text {th }}$ and the late $19^{\text {th }}$ century during the Edo (1615-1868) and the Meiji (1868-1912) eras.

\section{Correspondence}

C. Biron (carole.biron@u-bordeaux-montaigne.fr)

doi: $10.1255 /$ nir2017.015

Citation: C. Biron, F. Daniel, G. Le Bourdon, R. Chapoulie and L. Servant,

"Characterisation of organic colourants in ukiyo-e prints by Fourier transform near infrared fibre optics reflectance spectroscopy", in Proc. $18^{\text {th }}$ Int. Conf.

Near Infrared Spectrosc., Ed by S.B. Engelsen, K.M. Sørensen and F. van den Berg. IM Publications Open, Chichester, pp. 15-22 (2019). https://doi. org/10.1255/nir2017.015

\section{(c) 2019 The Authors}

This licence permits you to use, share, copy and redistribute the paper in any medium or any format provided that a full citation to the original paper is given, the use is not for commercial purposes and the paper is not changed in any way.

ISBN: 978-1-906715-27-4 
The Federico Torralba collection brings together more than a thousand Asian works of art. Among them, there are a hundred ukiyo-e signed by some of the greatest Japanese artists such as Utamaro, Hiroshige or Hokusai. Beyond the possibility to assess the state of conservation and degradation of the prints of the collection, the analyses conducted on these artworks aim at improving our knowledge on the history of art and on preparation techniques of the ukiyo-e by identifying the matters (nature, composition...) involved in their productions. The materials used, particularly colouring matters, constitute indicators on the typical resources available at a given period and allow us to deepen our knowledge on the technical, aesthetic or economic choices (for example natural or synthetic pigments, local or imported pigments). Such information may shed some light on the artistic trends, the cultural purposes and the socio-economic (trading activity, importation of new techniques...) impacts of these artworks. However, Japanese prints are thin and complex artworks, made with various compounds: inorganic and/or organic pigments and dyes bound with rice starch, printed on Japanese paper (Figure 1). Japanese paper is itself a complex system whose preparation depends on the paper- maker. Generally, various plant fibres are employed, like kozo or gampi. During the preparation, mineral fillers can be added, like calcium carbonate or white clay (kaolinite) in order to whiten the paper or increase its opacity. In addition, papers were sized with rice starch or dosa (animal skin glue and alum warmed in water) and sometimes dyed. ${ }^{14}$ For now, non-invasive methods have proven to be efficient for the identification of inorganic compounds but the identification of organic pigments remains a challenging task depending on their composition and concentration. In the case of paintings, NIR reflectance spectroscopy has been mainly employed for the identification of organic binders ${ }^{9,10}$ or of inorganic pigments. ${ }^{12,13}$ Thus we propose to evaluate the benefit of applying the NIR reflectance spectroscopy to probe traditional organic pigments used in Japanese ukiyo-e prints. For this purpose, analyses on reference isolated organic pigments and on model samples (colour chart) were performed. The main issues concerning the drawbacks of the techniques, such as the weakness of the pigment response and the overlapping of the NIR absorption bands (notably that originating from the paper substrate) will be discussed and a solution based on statistical treatment will be suggested.

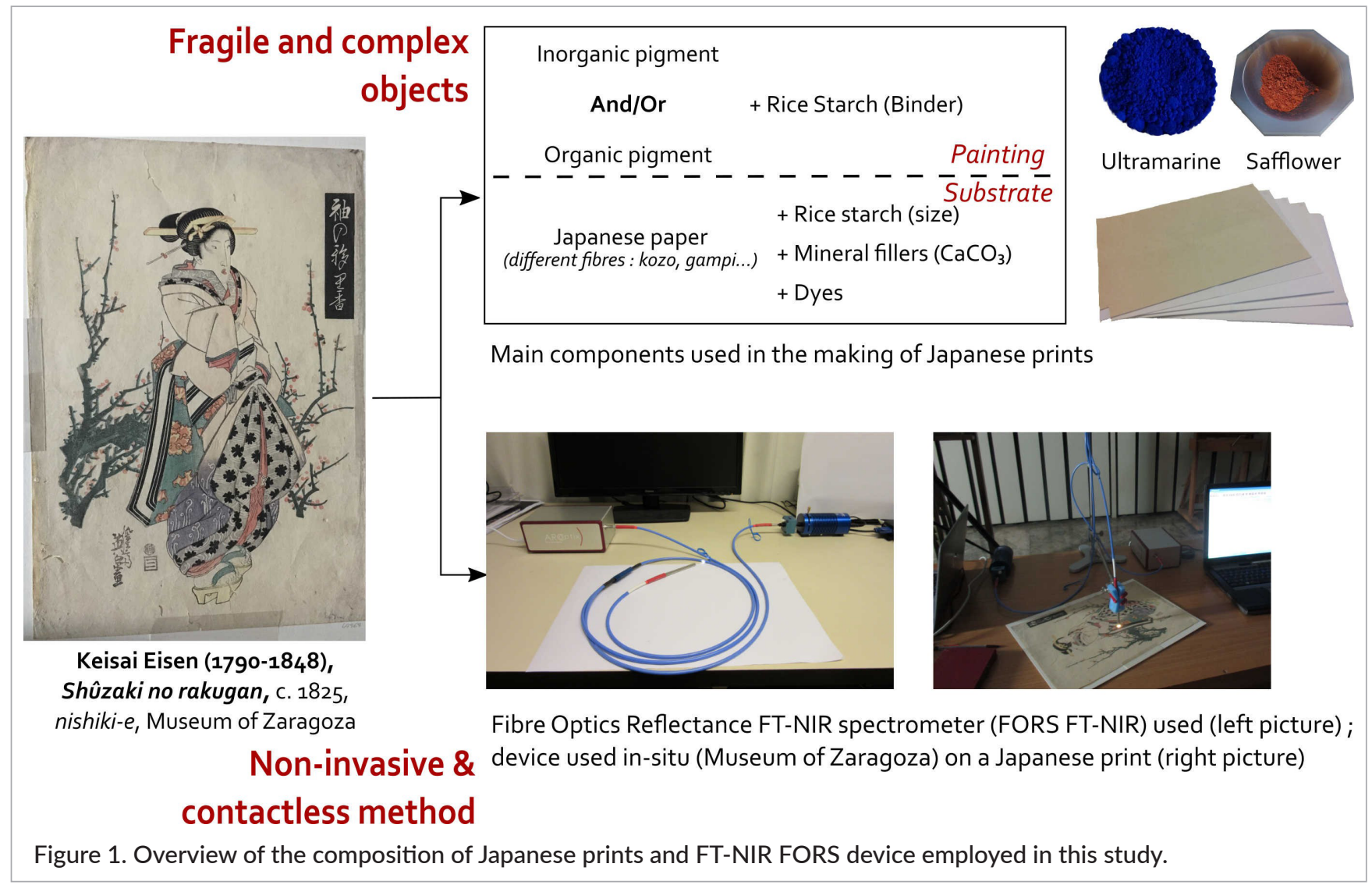




\section{Materials and methods}

\section{Reference materials and colour chart}

For this first approach, five organic pigments (indigo, safflower, gamboge, dragon's blood and cochineal), traditionally used in Asia, ${ }^{14,15}$ have been chosen for the building of a database dedicated to specific Japanese colouring matters in order to interpret future hyperspectral data in the Short Wave InfraRed range (SWIR, 1000-2500 nm) of a collection of Japanese ukiyo-e prints. Their main chromophore molecules ${ }^{16}$ are shown in Figure 2. Indigo and safflower are obtained by extracting and precipitating the chromophores, from the leaves of Persicaria tinctoria or Indigofera tinctoria for indigo and from the flowers of Carthamus tinctorius for safflower. Gamboge and Dragon's blood are materials obtained from the exudate of the trees of the EastAsian genus Garcinia (for gamboge) and fruits of the Daemenorops draco (for dragon's blood). Contrary to the other pigments, the red soluble dye of cochineal (Coccus cacti), carminic acid, needs to be fixed onto an inorganic substrate to form an organo-metallic complex, such as aluminium or calcium salts, in order to produce the solid pigment.

A reference colour chart was prepared using the five colourants under consideration. They were used alone mixed with a drop of rice starch made in the laboratory using powder of rice starch provided by Kremer Pigmente according to the following proportions: $5 \mathrm{~g}$ of powder of rice starch for $100 \mathrm{~mL}$ of distilled water. The mixtures were applied on wooden blocks and printed on paper. The selected paper is made of $100 \%$ cellulose (without coating or sizing) in order to avoid any contribution from other fibres or additives on infrared spectra such as lignin or inorganic fillers. Paper was slightly moistened with distilled water prior to printing.

\section{Near infrared spectroscopy}

In order to collect the reflectance spectra in the NIR range, a portable ARCoptix FT-NIR Rocket equipped with a photodiode InGaAs detector with a working range of $11,000-4000 \mathrm{~cm}^{-1}(900-2500 \mathrm{~nm})$ was used. The instrument is equipped with a HL2000 halogen lamp (Ocean Optics, 20 watts). Spectra were collected with an optical fibre bundle ( $Y$ shaped) which is constituted of seven optical fibres (fibre core size $400 \mu \mathrm{m}$, six illumination fibres around a collecting one; Figure 1). The measurement spot is of approximately $3 \mathrm{~mm}$ diameter.

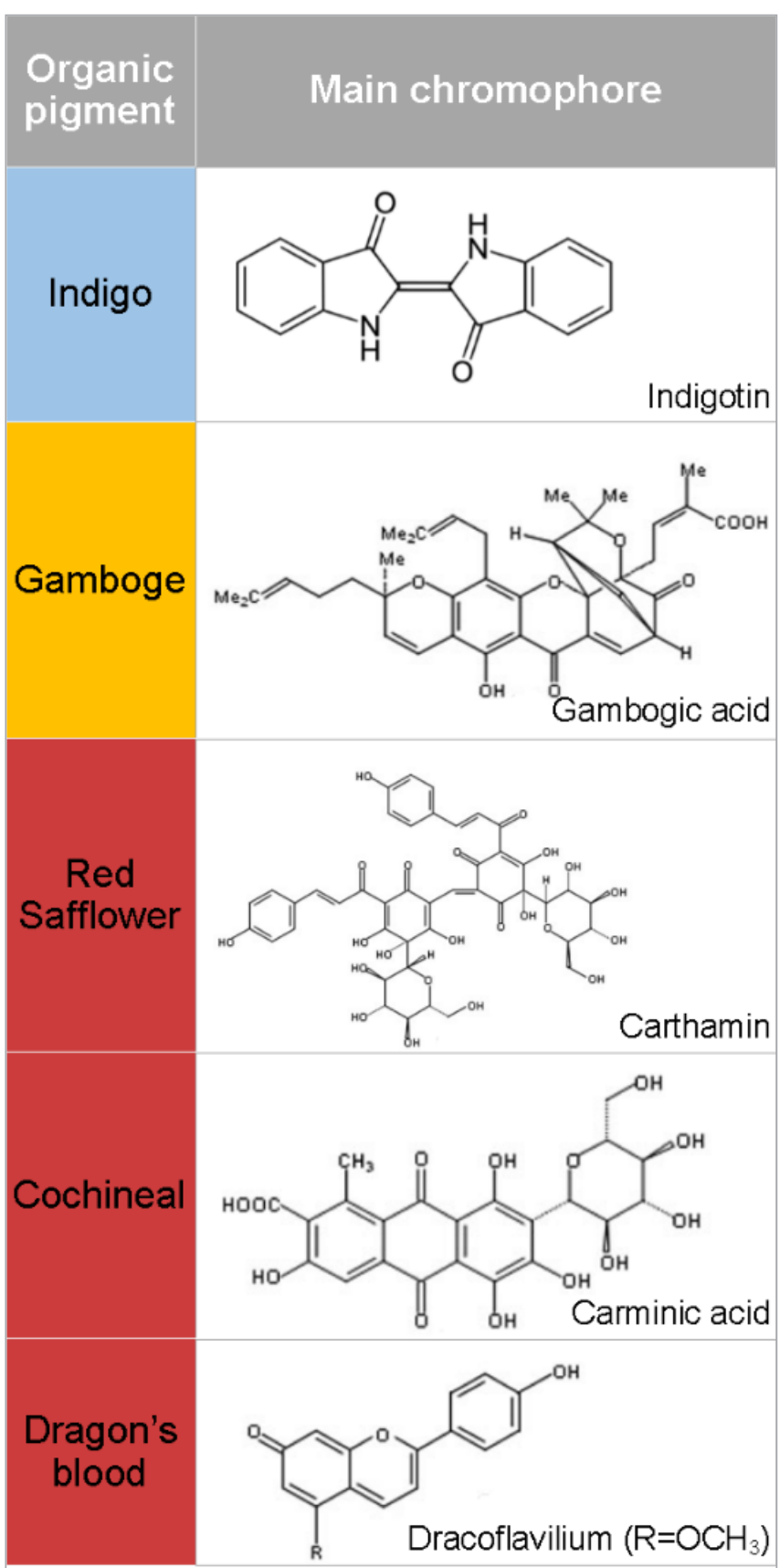

Figure 2. List of the pigments and their main chromophores.

The probe was positioned perpendicularly to the surface thanks to a clamp standing at the end of an articulating arm, at a working distance ranging between $3 \mathrm{~mm}$ and $5 \mathrm{~mm}$, in order to record the specular reflection component of the reflected light. Spectra were obtained by averaging 30 scans with an acquisition time about $20 \mathrm{~s}$ and at a $8 \mathrm{~cm}^{-1}$ spectral resolution. The instrument was calibrated using a white Spectralon ${ }^{\circledR}$ standard. 


\section{Experimental approach}

In the present work we applied infrared spectroscopy following two steps:

Building of a database of isolated pigments in order to identify the characteristic spectral signatures for isolated colourants

- Investigation of a reference colour chart to characterise complex pigment/dyes mixtures printed on paper

\section{Results and discussion Isolated compounds}

The first step consists in collecting reference spectra on neat standards (pigments, binder and substrate) in order to build a database of NIR spectra. Each isolated compound shows a specific signature in the NIR range (Figure 3). The paper and the rice starch are made of carbohydrates. The reference paper is made of $100 \%$ cellulose and its related bands are assigned mainly to $\mathrm{OH}$ groups: $2 \mathrm{v}(\mathrm{OH})$ between $7000 \mathrm{~cm}^{-1}$ and $6200 \mathrm{~cm}^{-1}$, combination of $\mathrm{OH}$ stretching and $\mathrm{OH}$ bending vibrations at about $5185 \mathrm{~cm}^{-1}$, principally due to adsorbed water, and combinations with $\mathrm{CO}$ stretching vibrations around $5495 \mathrm{~cm}^{-1}[\mathrm{v}(\mathrm{OH})+2 \mathrm{v}(\mathrm{CO})]$ and $4755 \mathrm{~cm}^{-1}$
$[\mathrm{v}(\mathrm{OH})+\mathrm{v}(\mathrm{CO})]$. The other bands can be assigned to $\mathrm{CH}$ group vibrations: combination of $\mathrm{CH}$ stretching and $\mathrm{CH}$ bending vibrations at $7280 \mathrm{~cm}^{-1}[2 \mathrm{v}(\mathrm{CH})+\delta(\mathrm{CH})]$ and at $4275 \mathrm{~cm}^{-1}[\mathrm{v}(\mathrm{CH})+\delta(\mathrm{CH})]$, first overtone of $\mathrm{CH}$ stretching vibration centred at $5600 \mathrm{~cm}^{-1}$ and other combination bands between $4270 \mathrm{~cm}^{-1}$ and $4000 \mathrm{~cm}^{-1} .{ }^{17}$ The spectrum of rice starch also presents bands ascribed to the carbohydrate signature between $7000 \mathrm{~cm}^{-1}$ and $6200 \mathrm{~cm}^{-1}[2 \mathrm{v}(\mathrm{OH})]$, at $4775 \mathrm{~cm}^{-1}[\delta(\mathrm{OH})+\mathrm{v}(\mathrm{CO})]$, between $6000 \mathrm{~cm}^{-1}$ and $5600 \mathrm{~cm}^{-1}[2 \mathrm{v}(\mathrm{CH})]$ and between $4330 \mathrm{~cm}^{-1}$ and $4000 \mathrm{~cm}^{-1}(\mathrm{CH}$ combination bands). ${ }^{17}$ The band at about $5170 \mathrm{~cm}^{-1}[\mathrm{v}(\mathrm{OH})+\delta(\mathrm{OH})]$ is assigned to the presence of water.

Regarding the pigments, safflower is a red pigment composed of carthamin, a quinochalcone $\mathrm{C}$-glycoside ${ }^{15}$ (Figure 2). Its NIR spectrum shows absorption regions corresponding to $\mathrm{OH}$ groups between $7000 \mathrm{~cm}^{-1}$ and $6200 \mathrm{~cm}^{-1}[2 \mathrm{v}(\mathrm{OH})]$ and at $5170 \mathrm{~cm}^{-1}[\mathrm{v}(\mathrm{OH})+\delta(\mathrm{OH})]$ which are mainly assigned to water. A pattern visible at about $5780 \mathrm{~cm}^{-1}$ is correlated to the first $\mathrm{CH}$ stretching overtones and the bands observed at $4330 \mathrm{~cm}^{-1}$ and $4250 \mathrm{~cm}^{-1}$ are due to $\mathrm{CH}$ stretching and $\mathrm{CH}$ bending combinations, which is consistent with the intense $\mathrm{CH}$ stretching mode measured in the mid-infrared spectrum. ${ }^{1}$ The spectrum of cochineal is characterised by weak

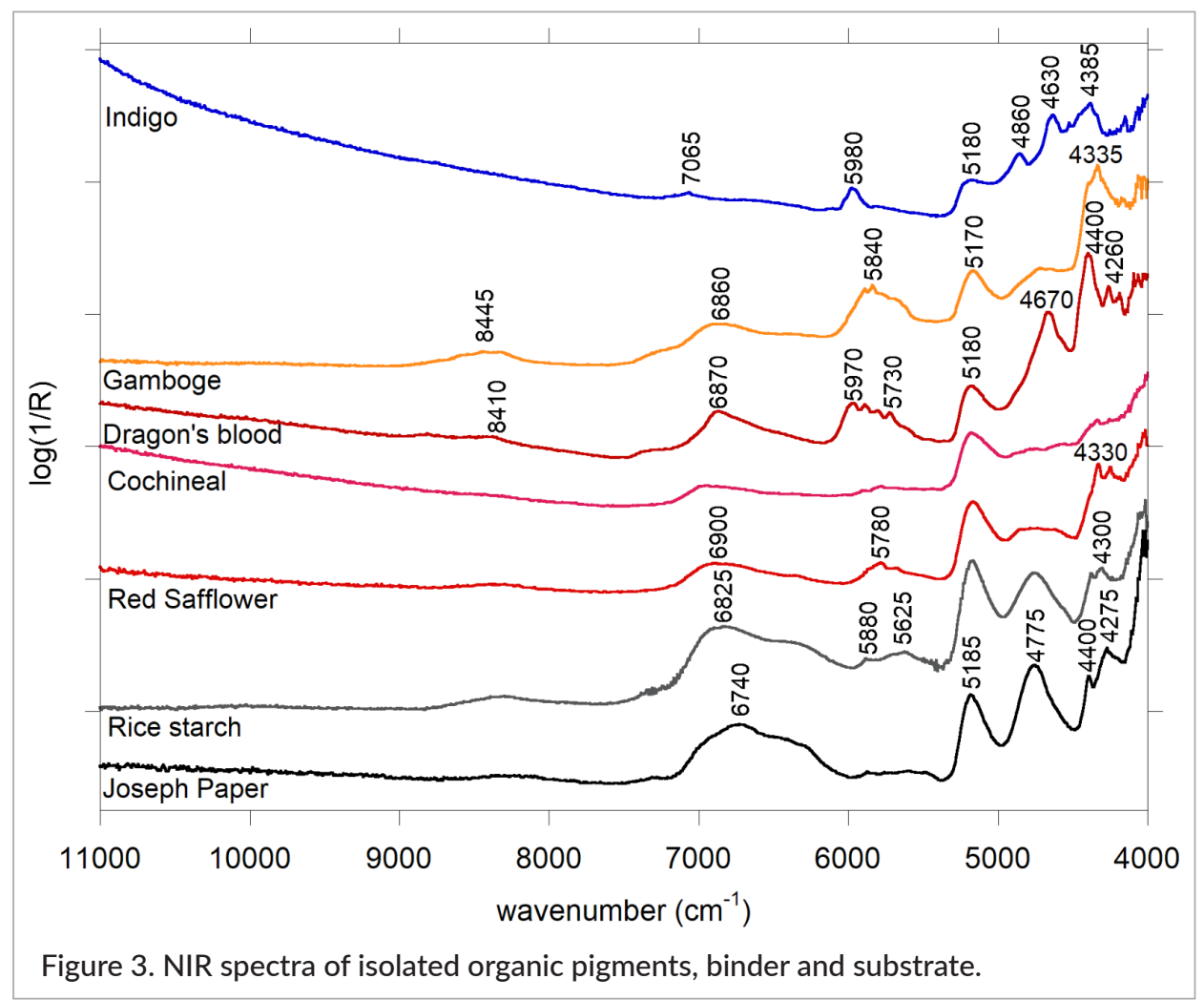


bands mainly at $6955 \mathrm{~cm}^{-1}[2 \mathrm{v}(\mathrm{OH})]$, between $5900 \mathrm{~cm}^{-1}$ and $5600 \mathrm{~cm}^{-1}[2 \mathrm{v}(\mathrm{CH})]$ and at $4330 \mathrm{~cm}^{-1}$ and $4260 \mathrm{~cm}^{-1}$ $\left[\mathrm{v}\left(\mathrm{CH}_{2}\right)+\delta\left(\mathrm{CH}_{2}\right)\right] .{ }^{17}$

Gamboge and dragon's blood are complex mixtures of several molecules including chromophores such as gambogic acid and dracoflavilium (Figure 2) as well as gum and/or resin components. ${ }^{14,18}$ The spectra of both pigments are characterised by absorption bands of $\mathrm{CH}$ groups. The first and second overtones of $\mathrm{CH}$ stretching vibrations are observed, respectively, between $6100 \mathrm{~cm}^{-1}$ and $5500 \mathrm{~cm}^{-1}$, very specific for dragon's blood with four defined absorption bands (5970, 5890, 5805 and $5730 \mathrm{~cm}^{-1}$ ), and between $9000 \mathrm{~cm}^{-1}$ and $8000 \mathrm{~cm}^{-1}$. The combination bands are located at about $7300 \mathrm{~cm}^{-1}$ and between $4350 \mathrm{~cm}^{-1}$ and $4000 \mathrm{~cm}^{-1}$. The broad absorption between $7000 \mathrm{~cm}^{-1}$ and $6200 \mathrm{~cm}^{-1}$ is ascribed to the first overtone of $\mathrm{OH}$ stretching vibrations. The bands centred at $5170 \mathrm{~cm}^{-1}$ for gamboge and at $5180 \mathrm{~cm}^{-1}$ for dragon's blood are assigned to $\mathrm{OH}$ stretching and bending combination. The dragon's blood spectrum also exhibits a specific band at $4670 \mathrm{~cm}^{-1}$ that can be assigned to the $\mathrm{CO}$ stretching and $\mathrm{CH}_{2}$ stretching combination. ${ }^{9,17}$

The spectrum of indigo exhibits several narrow but weak bands. Among them, the bands at 7065, 5180 and $4630 \mathrm{~cm}^{-1}$ are not ascribed to indigo but to kaolinite $\left[\mathrm{Al}_{2} \mathrm{Si}_{2} \mathrm{O}_{5}(\mathrm{OH})_{4}\right]^{19}$ which may be used as an extender in order to increase the quantity or the bulk of the pigment or to modify its colour. This result has been confirmed by energy-dispersive $\mathrm{x}$-ray spectroscopy (EDXS) analyses that indicate the presence of silicon and aluminium. The other bands are due to the molecule of indigo. The band centred around $5980 \mathrm{~cm}^{-1}$ is assigned to the first overtone of $\mathrm{CH}$ group stretching vibrations. In addition, combinations of $\mathrm{CH}$ group vibrations are certainly involved in numerous narrow bands between $4700 \mathrm{~cm}^{-1}$ and $4000 \mathrm{~cm}^{-1}$. Finally, the band located at about $4860 \mathrm{~cm}^{-1}$ is ascribed to the combination of $\mathrm{NH}$ stretching and bending vibrations. ${ }^{20}$

\section{Reference colour chart}

A colour chart of paints printed on paper was prepared in order to study mixtures of pigment and binder on paper mimicking the real case of Japanese prints. The NIR spectra of the depositions mainly present the spectral signatures of the paper substrate and the rice starch (Figure 4) with bands located at about 6750, 5185, 4760 and $4400 \mathrm{~cm}^{-1}$. For the pigments, only few spectral features can be distinguished on the spectra of dragon's blood, gamboge and indigo (indicated by arrows) due to overlapping bands of the paper and the starch.

Statistical methods can be used to explore further the infrared data in order to extract information from the spectra. In this first approach, Principal Component Analysis (PCA) was applied to discriminate and identify

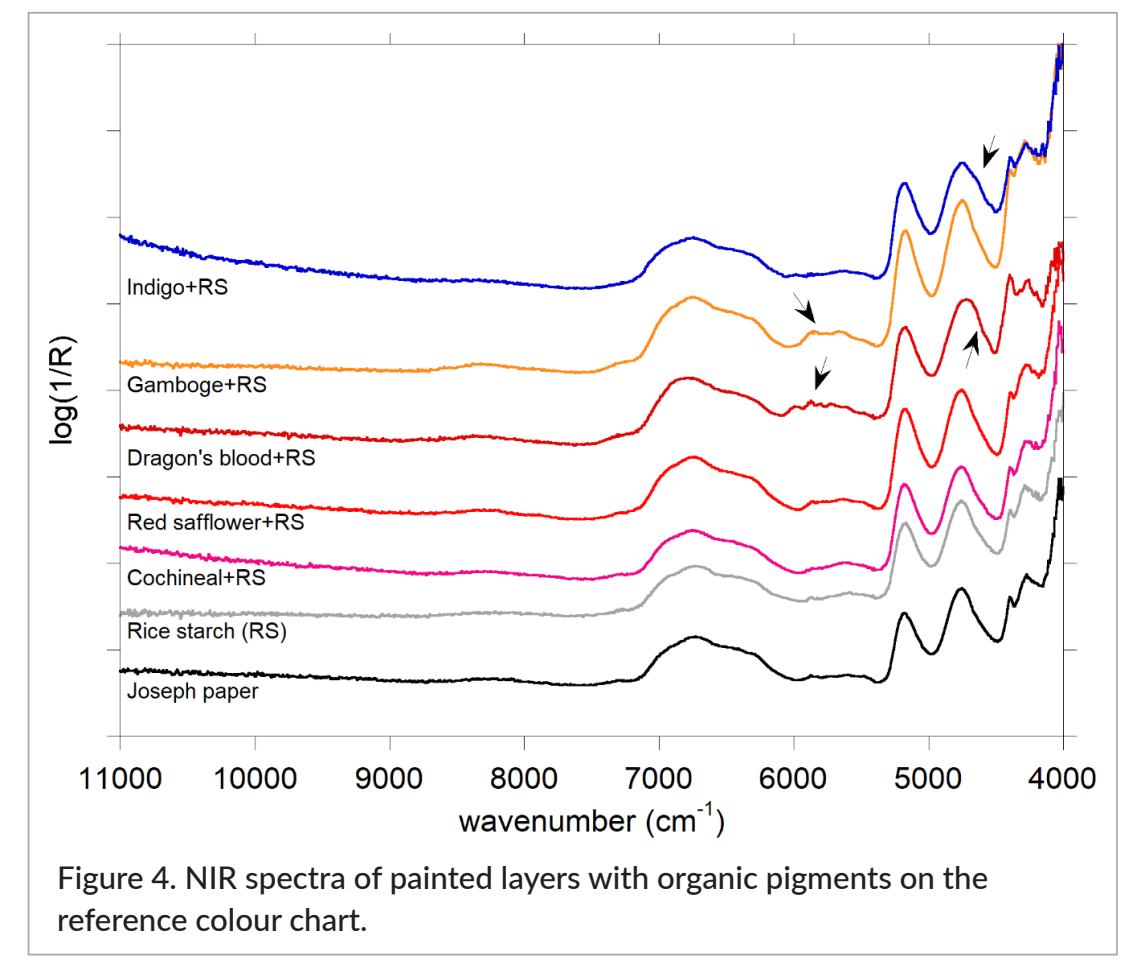


the pigments used in the mixtures on the depositions. Eight spectra have been acquired on each deposition on the colour chart for a total data set of 40 spectra. Data were pre-treated with first derivative SavitzkyGolay algorithm (polynomial order 1, 11 data points) followed by Standard Normal Variation (SNV) in the range $4100-8500 \mathrm{~cm}^{-1}$ (Figure $5 \mathrm{a}$ and b). The first four principal components $(\mathrm{PC})$ calculated by the statistical model explain a percentage of $92 \%$ of variability (PC1: 51.3\%, PC2: $20.4 \%$, PC3: $14 \%$ and PC4: $6.5 \%)$. The score plots of the PC1 against the PC2 and the PC1 against the PC4 are reported in Figure $5 \mathrm{c}$ and $5 \mathrm{~d}$. They show that the deposition made with dragon's blood can be clearly distinguished from the others thanks to PC1. Following the loading plots (not shown here), the vibrations that contribute to the PC1 are mainly due to those of dragon's blood with the well-defined and specific absorptions of the first overtones of the $\mathrm{CH}$ stretching vibrations between $6000 \mathrm{~cm}^{-1}$ and $5500 \mathrm{~cm}^{-1}$ as well as the $\mathrm{CO}$ stretching and $\mathrm{CH}_{2}$ stretching combination at about $4660 \mathrm{~cm}^{-1}$. The two score plots show that the depositions of safflower and cochineal are sparse and not well separated whereas the depositions of indigo and gamboge are, respectively, grouped. The vibrations of paper and rice starch strongly contribute to the PC2 loading plot (around $5200 \mathrm{~cm}^{-1}$ and $4765 \mathrm{~cm}^{-1}$ ) but features assigned to gamboge can be highlighted in the region of the first overtones of $\mathrm{CH}$ stretching vibrations (5900-5500 $\mathrm{cm}^{-1}$ ). In the case of the deposition of indigo, the discrimination can be clearly made thanks to the PC4 (Figure 5d) with the contribution of the characteristic vibrations of the molecule of indigo at about $5980 \mathrm{~cm}^{-1}$ and $4850 \mathrm{~cm}^{-1}$ but also of the extender kaolinite (around $7050 \mathrm{~cm}^{-1}$ ). The discrimination of safflower and cochineal still remains difficult as their NIR absorption bands are located in the same ranges as those of paper and starch $\left(7000-6200 \mathrm{~cm}^{-1}\right.$ and $5180 \mathrm{~cm}^{-1}$ ) and due to the weakness of their
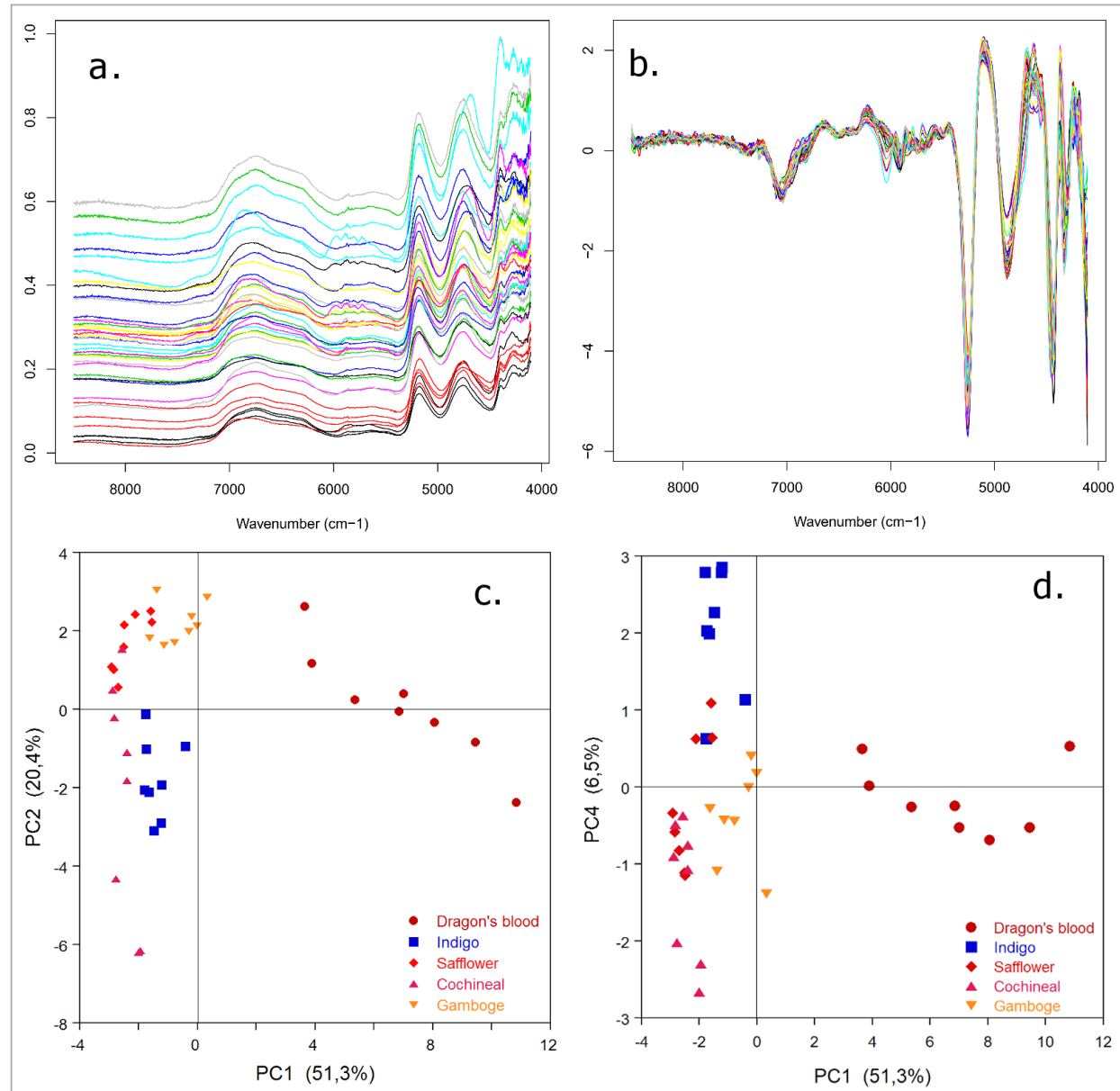

Figure 5. a NIR spectra of the depositions of organic pigments on the reference colour chart, b spectra after pretreatment, c PCA score plot for PC1 and PC2 and d PCA score plot for PC1 and PC4. 
specific absorptions $\left(6000-5600 \mathrm{~cm}^{-1}\right.$ and $4330 \mathrm{~cm}^{-1}$ and $\left.4260 \mathrm{~cm}^{-1}\right)$.

\section{Conclusion}

Portable NIR spectroscopy has been used for the first time on a set of five traditional Asian organic pigments involved in Japanese woodblock prints. Dragon's blood, indigo and gamboge pigments exhibit very specific bands in this range. However, in the case of paint deposition (mixture of pigment and binder) on paper substrate, the discrimination between the pigments appears difficult due to the overlapping spectral signatures of the paper and the rice starch. Chemometric treatments such as Principal Component Analysis has been considered in order to explore the data. For now, we highlight the possibility to discriminate between dragon's blood, gamboge and indigo depositions and suggest the use of spectral regions of interest, mainly related to the $\mathrm{CH}$ overtone and combination modes. Results also emphasise the importance of carefully paying attention to spectral contribution of each component in the building of the PCs. Indeed, pigments and more importantly paints are complex mixtures and in some instance, as it is the case for indigo, not only the chromophore molecule but also inorganic additives, which are not specific of the pigment, might be considered in the model. The pre-treatment of the data may be improved and other data processing schemes may be considered in the future such as clustering methods (Hierarchical cluster analysis, fuzzy C-means analysis) ${ }^{21}$ or the combination of specific NIR ranges with other spectral domains (mid-infrared range or Raman) in the statistical model which has been proved relevant for the discrimination of organic binders. ${ }^{10,22}$

\section{Acknowledgement}

This project (INDIGO, coord. F. Daniel) was supported by the University Bordeaux Montaigne and University of Bordeaux, the French State managed by the French National Research Agency within the framework of the cluster of excellence Laboratoire des Sciences Archéologiques de Bordeaux (ANR-10-LABX-52) and the CNRS.
We also acknowledge the International Council for Near Infrared Spectroscopy (ICNIRS) for supporting this work through the John Shenk Travel Grant.

\section{References}

1. C. Biron, G. Le Bourdon, J. Pérez-Arantegui, L. Servant, R. Chapoulie and F. Daniel, "Probing some organic ukiyo-e Japanese pigments and mixtures using non-invasive and mobile infrared spectroscopies", Anal. Bioanal. Chem. 410, 7043-7054 (2018). https://doi.org/10.1007/s00216-018-1305-2

2. M. Leona and J. Winter, "The identification of indigo and prussian blue on Japanese edo-period paintings", in Studies using Scientific Methods. Pigments in Later Japanese Paintings. Freer Gallery of Art, Occasional Papers, Smithsonian Institution, Washington, DC, USA (2003).

3. S. Pessanha, M. Manso and M.L. Carvalho, "Application of spectroscopic techniques to the study of illuminated manuscripts: a survey", Spectrochim. Acta B 71-72, 54-61 (2012). https://doi. org/10.1016/j.sab.2012.05.014

4. A. Mounier, G. Le Bourdon, C. Aupetit, C. Belin, L. Servant, S. Lazare, Y. Lefrais and F. Daniel, "Hyperspectral imaging, spectrofluorimetry, FORS and XRF for the non-invasive study of medieval miniatures materials", Heritage Sci. 2, 24-36 (2014). https://doi.org/10.1186/s40494-014-0024-z

5. F. Daniel, A. Mounier, J. Perez-Arantegui, N. PrietoTaboada, S. Fdez-Ortiz de Vallajuelo and K. Castro, "Hyperspectral imaging applied to the analysis of Goya paintings in the Museum of Zaragoza (Spain)", Microchem. J. 126, 113-120 (2016). https://doi. org/10.1016/j.microc.2015.11.044

6. S. Bruni, E. De Luca, V. Guglielmi and F. Pozzi, "Identification of natural dyes on laboratory-dyed wool and ancient wool, silk, and cotton fibers using attenuated total reflection (ATR) Fourier transform infrared (FT-IR) spectroscopy and Fourier transform Raman spectroscopy", Appl. Spectrosc. 65, 10171023 (2011). https://doi.org/10.1366/10-06203

7. C. Miliani, F. Rosi, I. Borgia, P. Benedetti, B.G. Brunetti and A. Sgamellotti, "Fiber-optic Fourier transform mid-infrared reflectance spectroscopy: a suitable technique for in situ studies of mural paint- 
ings", Appl. Spectrosc. 61, 293-299 (2007). https:// doi.org/10.1366/000370207780220840

8. M. Manfredi, E. Barberis, M. Aceto and E. Marengo, "Non-invasive characterization of colorants by portable diffuse reflectance infrared Fourier transform (DRIFT) spectroscopy and chemometrics", Spectrochim. Acta A 181, 171-179 (2017). https://doi. org/10.1016/j.saa.2017.03.039

9. M. Vagnini, C. Miliani, L. Cartechini, P. Rocchi, B.G. Brunetti and A. Sgamellotti, "FT-NIR spectroscopy for non-invasive identification of natural polymers and resins in easel paintings", Anal. Bioanal. Chem. 395, 2107-2118 (2009). https://doi. org/10.1007/s00216-009-3145-6

10. A. Pallipurath, J. Skelton, P. Ricciardi, S. Bucklow and S. Elliott, "Multivariate analysis of combined Raman and fibre-optic reflectance spectra for the identification of binder materials in simulated medieval paints", J. Raman Spectrosc. 44, 866-874 (2013). https://doi. org/10.1002/jrs.4291

11. V. Šuštar, J. Kolar, L. Lusa, T. Learner, M. Schilling, R. Rivenc, H. Khanjian and D. Koleša, "Identification of historical polymers using near-infrared spectroscopy", Polym. Degrad. Stabil. 107, 341-347 (2014). https://doi.org/10.1016/j.polymdegradstab.2013.12.035

12. M. Aceto, A. Agostino, G. Fenoglio, A. Idone, M. Gulmini, M. Picollo, P. Ricciardi and J.K. Delaney, "Characterisation of colourants on illuminated manuscripts by portable fibre optic UV-visible-NIR reflectance spectrophotometry", Anal. Methods 6, 14881500 (2014). https://doi.org/10.1039/c3ay41904e

13. S. Kogou, A. Lucian, S. Bellesia, L. Burgio, K. Bailey, C. Brooks and H. Liang, "A holistic multimodal approach to the non-invasive analysis of watercolour paintings", Appl. Phys. A 121, 987-1002 (2015). https://doi.org/10.1007/s00339-015-9425-4

14. J. Winter, East Asian Paintings. Materials, Structures and Deterioration Mechanisms. Archetype Publications, London, UK (2008).
15. D. Cardon, Le Monde des Teintures Naturelles. Belin, Paris, France (2014).

16. S. Bruni, V. Guglielmi and F. Pozzi, "Historical organic dyes: a surface-enhanced Raman scattering (SERS) spectral database on Ag Lee-Meisel colloids aggregated by $\mathrm{NaClO}_{4}$ ", J. Raman Spectrosc. 42, 12671281 (2011). https://doi.org/10.1002/jrs.2872

17. J. Workman and L. Weyer, Practical Guide and Spectral Atlas for Interpretative Near-Infrared Spectroscopy ( $2^{\text {nd }}$ Edn). CRC Press, Taylor \& Francis Group, Boca Raton, USA (2012).

18. D. Gupta, B. Bleakley and R.K. Gupta, "Dragon's blood: botany, chemistry and therapeutic uses", J. Ethnopharmacol. 115, 361-380 (2008). https://doi. org/10.1016/j.jep.2007.10.018

19. R.F. Kokaly, R.N. Clark, G.A. Swayze, K.E. Livo, T.M. Hoefen, N.C. Pearson, R.A. Wise, W.M. Benzel, H.A. Lowers, R.L. Driscoll and A.J. Klein, USGS Spectral Library Version 7. U.S. Geological Survey Data Series 1035 (2017). https://doi.org/10.3133/ ds1035

20. C. Tsiantos, M. Tsampodimou, G.H. Kacandes, M.S. del Río, V. Gionis and G.D. Chryssikos, "Vibrational investigation of indigo-palygorskite association(s) in synthetic Maya blue", J. Mater. Sci. 47, 3415-3428 (2012). https://doi.org/10.1007/ s10853-011-6189-x

21. A. Rammal, E. Perrin, V. Vrabie, I. Bertrand and B. Chabbert, "Classification of lignocellulosic biomass by weighted-covariance factor fuzzy C-means clustering of mid-infrared and near-infrared spectra", J. Chemometr. 31, e2865 (2017). https://doi. org/10.1002/cem.2865

22. S. Carlesi, M. Becucci and M. Ricci, "Vibrational spectroscopies and chemometry for non-destructive identification and differentiation of painting binders", J. Chem. 3475659 (2017). https://doi. org/10.1155/2017/3475659 